\title{
Completion norms collected from younger and older adults for 198 sentence contexts
}

\author{
MARLA J. HAMBERGER \\ The Neurological Institute, Columbia Presbyterian Medical Center, New York \\ DAVID FRIEDMAN \\ New York State Psychiatric Institute, New York \\ and \\ JEFFREY ROSEN \\ City University of New York, New York
}

\begin{abstract}
Completion responses were collected from younger and older adults for 198 highly constrained sentence contexts that were designed to elicit the same response (i.e., the best completion) in the vast majority of subjects. For each context, completions and their respective frequency of occurrence are provided. Overall, individuals of all ages produced highly similar terminal words. Results of formal analyses indicated that greater socioeconomic status and higher levels of education were mildly associated with a greater probability of producing a best completion response. Although increasing age also correlated with greater probability of producing a best completion, this very weak association would not preclude use of these stimuli with a wide age range.
\end{abstract}

The influence of semantic context on performance has been demonstrated in studies of free recall, recognition (Marcel, 1983), pronunciation latency (Kintch \& Mross, 1985; Kleiman, 1980), and lexical decision (Meyer, Schvaneveldt, \& Ruddy, 1975). The degree of constraint imposed by a context is proportional to the amount of information it provides. Thus, single words are less constraining than sentence contexts, and individual sentence contexts vary in the degree of constraint they impose. For example, "The girl recited the " has several plausible completions, and therefore is less constraining than the sentence, "There are 26 letters in the ___, which is more likely to produce a highly predictable response. Obviously, as the degree of constraint imposed by the context increases, the predictability of the missing term increases as well (Bloom \& Fischler, 1980). Taylor (1953) developed a method for categorizing sentence contexts according to their relative degree of constraint and for quantifying the responses (i.e., final words) that the sentence contexts elicit. According to the cloze method, subjects are asked to provide a word that has been omitted from text, which, in the present case, is the final word of the sentence. When a considerable proportion of subjects (e.g., $85 \%$ ) provide an identical response, the sentence is considered "highly constrained." According to this method, the particular response would have a "cloze probability" of .85 .

The ability to manipulate contextual constraint systematically can be useful in studies of semantic priming, read-

Correspondence should be addressed to $M$. J. Hamberger, The Neurological Institute, Columbia Presbyterian Medical Center, 710 West 168th St., New York, NY 10032 (e-mail: mh61@columbia.edu). ing, and memory. Although a variety of normative studies have been published for single words, word pairs, and categories, there are relatively few sets of standardized sentences in the literature. Since its publication, Bloom and Fischler's (1980) sentence completion norms have served as the principle source of sentence contexts for the majority of experiments employing sentences as stimuli. Using a subset of the Bloom and Fischler sentence contexts and a modification of the cloze procedure, Schwanenflugel (1986) published sentence completion norms for contexts of varying constraint. However, when experiments have required stimulus materials beyond the scope of these sets, investigators have been required to develop their own. Typically, these stimuli are idiosyncratic to the particular studies for which they were developed, their utilization is not based on the outcome of rigorously controlled norming procedures, and they are not readily accessible to other investigators. This lack of standardization limits interpretation of experimental findings as well as generalization across studies.

The set of sentences described here was developed for an investigation of the relationship between cognitive event-related potentials (ERPs) and semantic processing in patients with probable Alzheimer's disease (Hamberger, Friedman, Ritter, \& Rosen, 1995). Behavioral findings (e.g., Nebes, 1989) indicate that Alzheimer's patients show a predictable breakdown in semantic organization such that related items (e.g., apple, banana, pear) lose their distinction, whereas superordinate or more general concepts (e.g., fruit, clothing) remain intact. It has also been demonstrated in healthy young adults that under certain conditions, the amplitude of the N400 component of the ERP waveform (a negative peak that reaches maximum amplitude approximately $400 \mathrm{msec}$ poststimulus onset dur- 
ing a semantic processing task) is highly responsive to semantic relationships. Specifically, N400 amplitude varies inversely with the extent to which a word (or concept) has been primed by the immediately preceding semantic context. The purpose of the Hamberger et al. study was to determine whether the disruption in semantic processing in Alzheimer's patients, as shown by behavioral techniques, would also be observed in their $\mathrm{N} 400$ response, a physiological measure. A series of highly constrained sentence contexts was needed for a sentence priming task whereby there would be a strong probability that each sentence context would prime the same final word in every subject. The final word that was actually presented varied as a function of its semantic relatedness to the most expected final word of the sentence (i.e., the "best completion"). Subjects made speeded choice (sense vs. nonsense) decisions regarding the sensibility of each sentence, which were contingent on the meaning of the final word. ${ }^{\prime}$ Behavioral and ERP responses were recorded for the final word of each sentence. Concurrent recording of these measures provided information regarding the sequence and timing of cognitive events associated with the semantic processing evoked by the task.

The design of this particular study required a greater number of highly constrained sentence contexts than those provided by Bloom and Fischler (1980) and Schwanenflugel (1986), with the additional provision that all sentence completions would be nouns. Our intention was to develop a large pool of sentences that would elicit responses with a cloze probability of .85 or higher. It should be noted that our stimuli were heterogenous with respect to lexical associations within a given sentence context. Thus, for some contexts, the constraint on the final word may have been driven by a single word (e.g., "The pen ran out of ink."), whereas in others, it was driven by a sentence-level script (e.g., "The medication caused harmful side effects."). For our study, the means by which the sentence primed the final word was inconsequential. However, from this and other published data sets, it will be necessary for investigators concerned with the effects of lexical associations to select those contexts that are appropriate for their purposes.

The population sampled by Bloom and Fischler was limited to college-age students. Because we intended to test normal elderly, Alzheimer's patients, and young adults, cloze norms were obtained from 30 subjects over the age of 65 as well as from 100 younger subjects in order to determine the comparability of cloze norms produced by an older sample to those produced by a younger sample. Results of normative studies examining the effects of aging on measures such as confrontation naming (La Barge, Edwards, \& Knesevich, 1986) and category norms (Howard, 1980) have failed to find significant differences between older and young adults. On the basis of these reports, we expected to find similar response patterns between younger and older age groups.

\section{METHOD}

\section{Subjects}

One hundred younger $(72$ female, mean age $=29.9$ years, $S D=$ 8.3 years, age range $=18-56$ years $)$ and 30 older ( 18 female, mean age $=71.3$ years, $S D=4.5$ years, age range $=65-82$ years) volunteers participated in the sentence completion task. For the younger group, the mean number of years of formal education (EDUC) was $16.21,(S D=3.0$ years, range $=9-24$ years $)$, and mean rating of socioeconomic status (SES) according to the Hollingshead-Redlich index (Hollingshead \& Redlich, 1958) was 58.17, $(S D=14.8$, range $=20-82$, higher score $=$ lower SES). For the elderly, mean EDUC was $16.3(S D=11.0$, range $=8-24$ years $)$, and mean SES rating was $56.9(S D=21.6$, range $=20-91)$. There were no significant differences between age groups in SES or in years of formal education. All subjects were native English speakers, or had learned English prior to age 4.

\section{Stimuli}

One hundred ninety-eight sentence contexts were generated by the authors and their colleagues, who attempted to construct sentence contexts that would elicit the same final word in most subjects. Guidelines similar to those used by Bloom and Fischler (1980) were employed: (1) the addition of a single word would make each context a grammatically acceptable English sentence; (2) obvious clichés were avoided; (3) sentences were no longer than 10 words; and (4) a range of syntactic structures was included, although no formal manipulation of syntactic complexity was attempted.

\section{Procedure}

All subjects recelved an 8-page booklet. The cover page provided space for demographic information (i.e., age, sex, occupation, and educational background) and contained the following instructions (modified from Bloom \& Fischler, 1980):

On the following pages are a large number of sentences, each with the final word left blank. Your task is simply to read each sentence at your normal rate, and write down the word that first occurs to you as a likely end of that sentence. For example, if the sentence "frame" were: "The party did not end until ___," possible responses might include dawn, three, late, midnight, and so forth. Don't try to be either unique or average; just be natural. You should keep within the following bounds, however: (1) Only one response word per sentence; (2) The word should "make sense" of the sentence and be from an appropriate class of words (nouns, verbs, adjectives, etc.); (3) English words only; (4) No proper names, hyphenated, or contracted words; (5) Try to avoid repetitions. For some of the sentences the response will seem obvious; for others, several words may seem possible. Please print clearly

The succeeding pages each contained 30 sentence contexts followed by a blank underscore (with the exception of the final page, which contained the last 18 sentence contexts). Sentence order was identical for all subjects.

\section{Data Analysis}

The probability of each response was calculated for each sentence separately for the two age groups. Additionally, a frequency score was obtained for each subject, indicating the number of sentence contexts that were completed with "best completions" (i.e., the final word with the greatest cloze probability for each sentence). This score, referred to as the best completion score (BC), was the measure by which subjects were compared. The effects of age, SES, and EDUC on BC were examined via Pearson correlations and $t$ tests. For $t$-test analyses of EDUC, subjects were categorized according to whether or not they had completed college ( $>$ or $\leq 16$ years) ${ }^{2} \mathrm{Me}$ dian splits were utilized to perform $t$ tests exploring the effects of SES. The effect of sentence length was assessed by correlating cloze probability with the number of words per sentence.

Illegal responses (i.e., those that violated the instructions) were defined as responses that (1) consisted of 2 words, (2) rendered the sentence agrammatical, or (3) were semantically anomalous. The extent to which these were provided in each group was examined by comparing within-group percentages (i.e., number of illegal responses per number of subjects in each group). 


\section{RESULTS}

The appendix lists the sentence contexts, their terminal response words, and their respective cloze probabilities separately for the younger and older groups. Responses provided by older subjects that were different from those provided by younger subjects are marked by an asterisk. Sentence contexts are presented in order of decreasing contextual constraint: Response words elicited by each context are listed in descending order of frequency of response. The number of words in a sentence did not correlate with the cloze probability of the final word.

\section{Effects of Age}

As can be seen in the appendix, the elicited response words and their associated cloze probabilities were remarkably similar for the younger and older subjects. Additionally, the propensity to complete a sentence with the most frequent response, as assessed by BC scores, was comparable for both groups. Mean $\mathrm{BC}$ scores for the younger and older groups, respectively, were $178.1(S D=9.4$, range $=151-192)$ and $181(S D=5.9$, range $=165-190)$ from a possible total of 198. Results of $t$-test analysis indicated that these scores were not significantly different. The distributions of BC scores for the younger and older groups are shown in Figure 1. Results of the KolmogorovSmirnov two-sample test revealed no significant differ-
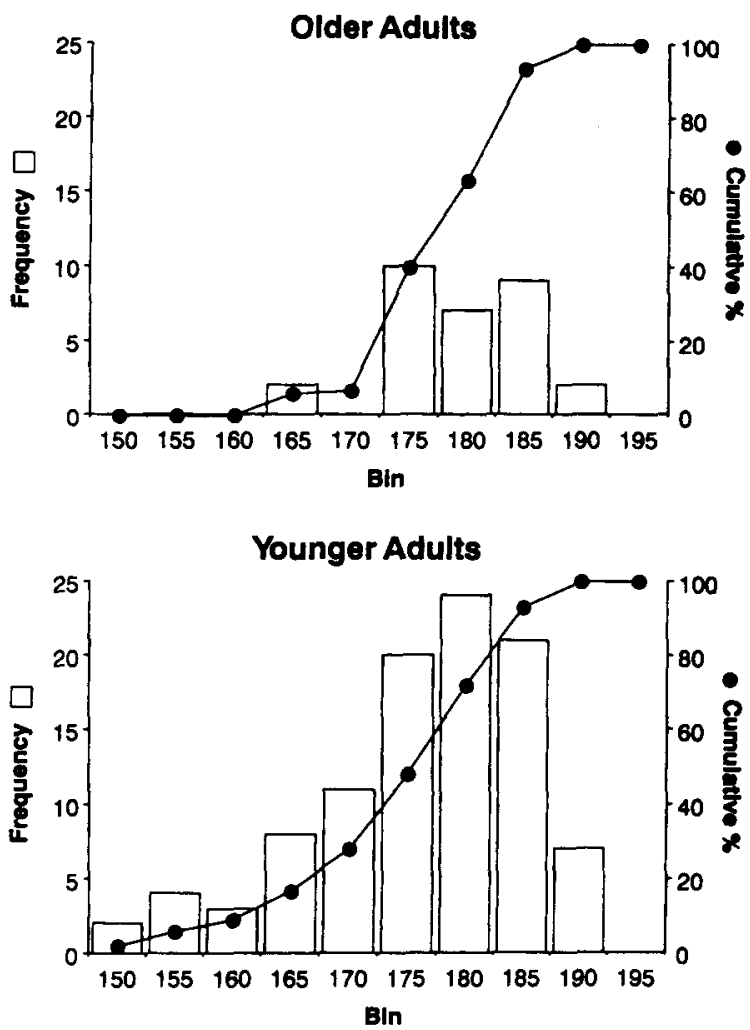

Figure 1. Frequency histograms and cumulative relative frequency distributions of best completion scores for older (top) and younger (bottom) adults. Bin size $=5$.
Table 1

Mean Best Completion Scores for Younger and Older Adults as a Function of SES and EDUC

\begin{tabular}{ccc}
\hline & \multicolumn{2}{c}{ GC Score } \\
\cline { 3 - 3 } \multicolumn{1}{c}{ Younger } & & $S D$ \\
\hline EDUC $\leq 16$ years $(n=60)$ & 175.6 & 9.7 \\
EDUC $>16$ years $(n=40)$ & 181.6 & 7.9 \\
SES below median $(n=57)$ & 175.7 & 9.5 \\
SES above median $(n=43)$ & 181.3 & 8.2 \\
\multicolumn{1}{c}{ Older } & & \\
EDUC $<16$ years $(n=20)$ & 179.8 & 4.8 \\
EDUC $>16$ years $(n=10)$ & 183.2 & 7.2 \\
SES below median $(n=15)$ & 179.8 & 5.6 \\
SES above median $(n=15)$ & 182.3 & 6.4 \\
\hline
\end{tabular}

Note-EDUC, mean number of years of formal education; SES, socioeconomic status.

ences between the shapes of these two distributions. The correlation between age and $\mathrm{BC}$ was weak, although statistically significant $(r=.18, p<.05)$, probably due to the large sample size.

The number of illegal responses was tallied separately for the younger and older groups. A total of $24(24 \%)$ and $7(23 \%)$ illegal responses were generated by the younger and older groups, respectively. Formal analysis was not performed as these proportions were very similar.

\section{Effects of Demographic Variables}

Table 1 shows mean BC scores of subjects in the younger and older groups categorized according to EDUC and SES levels. Within the younger group, $t$ tests revealed mild but significant effects of EDUC $[t(98)=3.14, p<.01]$ and SES $[t(98)=3.12, p<.01]$; subjects with more education and higher socioeconomic status provided a greater percentage of best completions. The pattern in the older group was similar to that observed for the younger adults. Results of $t$-test analyses were not significant, however, probably due to the relatively small sample size. Results of correlational analyses including all 130 subjects were fairly consistent with the data reported above. Although the correlation between EDUC and $\mathrm{BC}$ was not significant, a mild but significant correlation between SES and BC was revealed $(r=-.24)$, again showing a trend in which higher socioeconomic status was associated with an increased probability of producing a best completion.

\section{DISCUSSION}

As intended, the majority of sentence contexts were of high contextual constraint, and therefore can be utilized to study the effects of semantic priming and sentence processing of highly predictable words. Although the response patterns between younger and older adults were quite similar, formal analyses revealed a mild trend in which older subjects were more likely to generate a best completion response. Analyses also indicated that subjects with higher levels of education and greater socioeconomic status were more likely to produce a best completion response. Although the outcomes 
of these analyses were significant, it should be noted that the correlations were relatively weak, accounting for no more than $6 \%$ of the variance. Additionally, results of $t$ tests were significant only when sample size was large. Thus, the relationships between these demographic variables and performance should be considered weak at best, indicating that the current sentence contexts can be effectively utilized with individuals across the lifespan.

\section{REFERENCES}

Bloom, P. A., \& Fischler, I. (1980). Completion norms for 329 sentence contexts. Memory \& Cognition, 8, 631-642.

Hamberger, M. J., Friedman, D., Ritter, W., \& Rosen, J. (1995). Event-related potential and behavioral correlates of semantic processing in Alzhermer's patients and normal controls. Brain \& Language, 48, 33-68.

HollingShEAD, A. B., \& ReDlich, F. C. (1958). Social class and mental illness. New York: Wiley.

HowaRD, D. V. (1980). Category norms. A comparison of the Battig and Montague (1969) norms with the responses of adults between the ages of 20 and 80 . Journal of Gerontology, 35, 225-231.

KINTCH, W., \& Mross, E. F. (1985). Context effects in word recognition. Journal of Memory \& Language, 24, 336-349.

Kleiman, G. M. (1980). Sentence frame contexts and lexical decisions Sentence acceptability and word relatedness effects. Memory \& Cognition, 8, 336-344.

LaBarge, E., Edwards, D., \& Knesevich, J. W. (1986). Performance of normal elderly on the Boston Naming Test. Brain \& Language, 27 380-384.

MARCEL, A. J. (1983). Conscious and unconscious perception: Experiments on visual masking and word recognition. Cognitive Psychology, 15, 197-237.

Meyer, D., Schvaneveldt, R., \& Ruddy, M. (1975). Loci of contextual effects on visual word-recognition. In P. M. A. Rabitt \& S. Dornic (Eds.), Attention and performance V (pp. 98-1 16). New York: Academic Press.

Nebes, R. (1989). Semantic memory in Alzheımer's disease. Psychological Bulletin, 106, 377-394.

SchWANEnflugel, P. J. (1986). Completion norms for final words of sentences using a multıple production measure. Behavior Research Methods, Instruments, \& Computers, 18, 363-371.

TAYLOR, W. L. (1953). "Cloze" procedure: A new tool for measuring readability Journalism Quarterly, 30, 415 .

\section{NOTES}

1. Only the sentence contexts and the final words elicited during the sentence completion task are included here. The sentence contexts and the alternative final words utilized in the Hamberger et al. (1995) study are available in Hamberger et al. or on request.

2. Instead of median splits, we explored the effect of EDUC on the basis of whether or not individuals had completed college, as we belıeved that this criterion was conceptually more meaningful.

\section{APPENDIX}

Sentence contexts, completions, and cloze probabilities (younger/older) for 198 sentence contexts. Sentence completions are presented in italics. First/second cloze probabilities in parentheses are based on completions of 100 younger and 30 older volunteers, respectively; ${ }^{*}$ indicates a response given by subject(s) in the older group only. Illegible responses were omitted.

1. She sipped the soda through a straw $(100 / 100)$.

2. Joe hit the baseball with the bat (100/93.3), baseball bat*(3.3).

3 . Don't cross the street when you see a red light $(100 / 100)$.

4 . We washed our hands with soap and water $(100 / 100)$.

5 . He put the ring on her finger $(100 / 100)$.
6. The church had a beautiful stained glass window (100/100).

7. He fried an egg and two strips of bacon $(100 / 100)$.

8. The tired runner stopped to catch his breath (100/100).

9. The story had a happy ending $(100 / 100)$.

10. The Indian carried a bow and arrow $(100 / 100)$.

11. The impatient driver honked his horn $(100 / 100)$.

12. The dentist pulled his wisdom tooth $(100 / 100)$.

13. The magician pulled the rabbit out of the hat $(100 / 100)$.

14. The fly got caught in the spider's web $(100 / 96.7)$, nest $^{*}(3.3)$.

15. The pen ran out of ink $(100)$.

16. The old man sat on the park bench (100/100).

17. Birds fly south for the winter $(100 / 100)$.

18. She looked at herself in the mirror $(100 / 100)$.

19. The dog buried a bone $(100 / 100)$.

20 . She won a new washer and dryer $(100 / 100)$.

21 . He looked up the word in the dictionary $(100 / 100)$.

22. The medication caused harmful side effects $(100 / 100)$.

23 . The open window let in some fresh air $(100 / 100)$.

24 . She put fresh sheets on the bed $(100 / 100)$.

25 . He got a tissue and blew his nose $(100 / 100)$.

26 . Bob covered his pancakes with maple syrup $(100 / 100)$.

27. He kept his wallet in his jacket pocket (100/100).

28 . The car had a flat tire $(100 / 100)$.

29. There are twenty-six letters in the alphabet (99/96.7), mail (1).

30 . The poster was hung with masking tape $(99 / 100)$, paper (1).

31. Look both ways before crossing the street (99/93.3), road (1/3.3), gutter* (3.3).

32. The gift was in a cardboard box (100/99), container (1).

33. The boys played cops and robbers $(99 / 100)$, thief $(1)$.

34 . The noise woke her in the middle of the night $(99 / 100)$, afternoon (1).

35. He got a ticket for going over the speed limit ( $99 / 100)$, zone (1).

36 . She ate with a knife and fork (99/100), spoon (1).

37 . He threw a penny into the wishing well (99/96.7), fountain (1).

38. The house was surrounded by a picket fence $(99 / 100)$, line (1).

39. He chopped down the tree with an ax $(99 / 100)$, blade (1).

40. I sewed on the button with a needle and thread (99/100), string (1).

41. The messenger bowed to the king and queen (99/100), left (1).

42. He dried his hands on a paper towel (99/96.7), cloth (1), nap$\mathrm{kin}^{*}(3.3)$.

43. The murderer received a life sentence ( $99 / 100)$, prison (1).

44. Jot it down on a piece of paper (99/100), piece (1).

45. She solved the crossword puzzle $(99 / 100)$, game (1).

46. He sailed across the seven seas $(99 / 100)$, lakes (1).

47. She let her daughter pierce her ears $(98 / 100)$, earlobes (2).

48. He was condemned to the electric chair (98/100), bill (2).

49. The gambler liked to roll the dice (98/100), deck (1), money (1).

50 . He flushed the toilet (98/100), john (1), commode.

51. The teller sold him a round-trip ticket (98/96.7), cruise (1), trip (1), fare* (3.3).

52. She polished her finger nails (98/96.7), bowls (1), ring (1/3.3).

53. She was afraid of the lightning and thunder $(98 / 100)$, rain (2).

54 . The little boy marched like a wooden soldier (98/96.7), marionette (1), toy (1), gun* (1/3.3).

55. The construction worker wore a hard hat (98/96.7), helmet (2/3.3).

56. The bowler knocked down all ten pins (98/96.7), balls (1/3.3), wickets (1).

57. The girls got into a pillow fight (98/100), sack (1), talk (1).

58. The immigrant wanted to become a U.S. citizen $(98 / 100)$, senator (1), president (1).

59. On her diet she only lost one pound (98/100), inch (1), ounce (1).

60. She sang soprano in the church choir (98/93.3), auditorium (98), chorus (1), balcony* (3.3). 
61. The little girl wanted a piggyback ride (98/96.7), race (1), bank (1/3.3).

62. The scientist studied the bacteria under a microscope $(98 / 100)$, lens (1), slide (1).

63. The superstitious man would not walk under a ladder $(98 / 100)$, plank (1), scaffold (1).

64. She bought a new pair of running shoes (97/83.3), sneakers (1/13.3), shorts (1), skates* (3.3).

65. The hero was given a twenty-one gun salute (97/100), shot (2), shells (1).

66 . He couldn't see without his glasses $(97 / 90)$, eyeglasses $(2 / 10)$, eyes (1).

67. She went to the grocers to do some shopping (97/90), favors (1), marketing (1/6.7), food (1).

68. They rode down to the lobby in the elevator (97/100), car (1), hotel (1), shuttle (1).

69. They played catch with a tennis ball $(97 / 86.7)$, racquet $(2 / 13.3)$, player (1).

70. The ambulance rushed him to the hospital (97/96.7), accident (1), emergency room (1), scene (1), clinic* (3.3).

71. The magician waved his magic wand (96/100), stick (2), baton (1), bat (1).

72. Pat blew out all the candles on the cake (96/93.3), birthday cake (3/3.3), table (1/3.3).

73. They enjoyed looking through the family album $(96 / 100)$, photos (1), photo album (1), tree (1), pictures (1).

74. Let me take your hat and coat (96/93.5), gloves $(3 / 6.7)$.

75. She put the flowers and water in a vase (96/96.7), grave (1), jar (1/3.3), pitcher (1), pot (1).

76. The boy put an apple on the teacher's $\operatorname{des} k(96 / 100)$, head (3), table (1).

77. The turtle pulled his head into its shell $(96 / 90)$, neck $(2 / 3.3)$, back (1), body (1/3.3).

78. The wound left a permanent scar (96/96.7), mark (2), damage (1), limp (1), injury* (3.3).

79. For a headache she takes two aspirin (96/96.7), Anacin (1), Bufferin (1), pills (1), tablets (1/3.3).

80. She told the brat to go stand in the corner (96/100), dark (1), line (1), road (1), street (1).

81 . The landlord came to collect the rent $(96 / 100)$, insurance (2), money (1), rent money (1).

82. The athlete won a gold medal (96/86.7), ribbon (1), glove (1), ring (1), trophy* (3.3), chain* (3.3), uniform*(3.3), star*(3.3).

83. He liked the scent of her new perfume (96/96.7), cologne (1), deodorant (1), flowers (1), fragrance (1), powder* (3.3).

84. The prince awakened her with a kiss $(95 / 100)$,jolt (1), song (1), princess (1), gun (1), yell (1).

85. A cleaning woman scrubbed the floor (95/96.7), bathroom (1/3.3), kitchen (1), rug (1), sink (1), stove (1).

86. I look in the phone book to find the number (95/83.3), address (3), Andrews (1), phone \# (1/16.7).

87. The unhappy marriage ended in a divorce (95/100), separation (2), fight (1), break (1).

88. They gossiped during their coffee break $(95 / 90)$, hour $(4 / 3.3)$, clotch (1/6.7).

89. The tree died after it was struck by lightning (95/96.7), car (5), truck* (3.3).

90. She liked to eat buttered popcorn at the movies (95/93.3), cinema (2/3.3), party (2), theatre (1), store (1), game* (3.3).

91. The bride's face was covered by a veil $(95 / 100)$, frown (1), mask (1), scar (1), smile (1).

92. He shouted so loud he lost his voice (95/93.3), hearing (3/3.3), balance (1), head (1), hair (1), breath* (3.3).

93. The poor student was expelled from school $(95 / 96.7)$, class (4/3.3).
94. There wasn't any toothpaste left in the tube (95/96.7), bathroom (2/3.3), cabinet (2), house (1), medicine chest (1).

95. A bicycle has two wheels $(95 / 93.3)$, pedals $(4 / 6.7)$, handlebars (1).

96. She carried her lunch in a picnic basket (95/86.7), box (4/6.7), bag (1/6.7).

97. The sleepy man had bloodshot eyes $(92 / 100)$, wound (5).

98. Instead of wine the children drank grape juice $(94 / 100)$, soda (4), cooler (1), drink (1).

99. The hat was decorated with ostrich feathers (94/96.7), colors (1), lining (1), pictures (1), shells (1), eggs (1), plume* (3.3).

100. He was murdered in cold blood (94/100), night (2), weather (2), daylight (1), rain (1).

101. She had to change the baby's diaper (94/96.7), Pampers (4), clothes (1), name (1), pants (1).

102. The glee club sang a song (94/86.7), tune (4), chorus (1), hymn (1), concert* $(1 / 3.3)$, ballad $^{*}(1 / 3.3)$, madrigal $*(1 / 3.3)$, melody* (1/3.3).

103. Chew before you swallow your food (94/100), gum (4), meat (2).

104. The first graders had milk and cookies (94/83.3), cereal (2), crackers (2/6.7), biscuits (1), bread (1).

105. We had bacon and eggs for breakfast (94/96.7), dinner (4), lunch $(2 / 3.3)$.

106. He went out to warm up the car $(94 / 96.7)$, engine (2), bike (1), night (1), bar-b-que (1), coffee (1/3.3).

107. The mouse ate the cheese (93/100), apple (1), cat (1), fly (1), poison (1), crumbs (1), roach (1), termite (1).

108. The unlucky gambler lost all of his money (93/80), chips (1/6.7), savings (1/3.3), earnings (1), shirts (1), possessions (1), belongings* $(3.3)$, winnings* $(6.7)$.

109. The shepherd watched his flock of sheep $(93 / 100)$, geese (2), lambs (2), goats (1), animals (1).

110. The cop loaded his gun $(93 / 80)$, pistol $(4 / 13.3)$, revolver (3/6.7).

111. The beggar asked for some spare change (93/86.7), coins (2), food (2/3.3), money (2/6.7), ribs (1), dimes* (3.3).

112. The children went to camp for the summer (93/96.7), week (2), weekend (1), day (1), month (1), first time (1), night (1/3.3).

113. The fireman unwound the hose (93/96.7), coil (1), clock (1), cord (1), engine (1), rope (1), victim (1), fire (1), pipe* (3.3).

114. The car stopped when I stepped on the brake (93/83.3), curb (2/3.3), street (2), gas (1/3.3) gas pedal (1), pedal (1/3.3), treadle* $(3.3)$, roadway* $(3.3)$.

115. The cow gave birth to the calf (93/96.7), baby (3), heifer (2), baby cow (1), cow (1), cub* (3.3).

116. He walked up the steps and rang the bell $(92 / 90)$, doorbell (7/10), gong (1), buzzer (1).

117. The heavy rains caused a flood (92/96.7), storm (5), downpour (1), puddle (1), flooding (1/3.3), jam (1).

118. The executive dictated a letter to his secretary $(92 / 100)$, colleagues (2), dictaphone (2), client (2), people (1), boss (1).

119. The cat killed a field mouse (92/96.7), rat (7), of mice (1), sparrow* $^{*}(3.3)$.

120. If you ride bareback you don't need a saddle $(92 / 100)$, shirt (5), horse (2), cushion (1).

121. The interview went well and he got the job (91/93.3), promotion (3/3.3), "A" (1), answer (1), information (1), story (1), hire (1), position (1/3.3).

122. He ate a plate of franks and beans (91/96.7), fries (3), hamburgers (2), chili (1), chips (1), eggs (1), rolls (1), sauerkraut $^{*}(3.3)$. 
123. The campers pitched a tent (91/96.7), fire (2), game (1/3.3), fish (1), party (1), water (1).

124. She was glad they offered her maternity leave (91/93.3), clothes $(5 / 3.3)$, benefits $(1 / 3.3)$, insurance (1), payments (1), robes (1), suits (1).

125. The butcher delivered an entire side of beef $(90 / 96.7)$, meat (3), cow (1), lamb (1), pig (1), ribs (1), steed (1), bacon* (3.3).

126. The skater fell on the ice (90/100), floor (3), ground (3), sidewalk (1), rink (1), pond (1).

127. The earth spins on its axis (90/83.3), axle (5/10), orbit (2/6.7), rings (1), side (1).

128. The cereal was fortified with vitamins and minerals $(90 / 66.7)$, nutrients (3), iron (2/3.3), protein (2/3.3), bran (1/10), D(1), nutrition (1), calcium* (3.3), fruits* (3.3), fiber* (3.3), raisins* (3.3).

129. She had a run in her stockings (90/93.3), pantyhose (2/3.3), shorts (1), money (1), hose (1), nylon (1), shoes (1), stomach (1), tights (1), yard (1), garden* (3.3).

130. The couple applied for a marriage license (90/96.7), certificate (8/3.3), counselor (2).

131. The lost dog was returned to his owner (90/73.3), home (3/3.3), master (3/23.3).

132. We wrapped the leftovers in tin foil (90/93.3), cans (5/3.3), paper (3), containers (2/3.3), pans (1).

133. Please wipe your feet on the mat (89/83.3), doormat (4/3.3), rug (4/3.3), newspaper (1/3.3), towel (1), floor (1).

134. She had a cold and a sore throat (89/93.3), nose (7/3.3), lip (1/3.3), muscle (1).

135. Jane returned the books to the library (89/93.3), store (5), shelf (2/3.3), owner (1), teacher (1), bookcase (1/3.3).

136. She guessed the answer to the question (88/90), problem (4), puzzle (2/3.3), quiz (1), riddle (1), test (1/3.3), class (1), game* (3.3).

137. The records were kept in a filing cabinet (88/100), drawer (3), box (1), bin (1), case (1), fashion (1), folder (1), system (1), room (1).

138. The man closed the curtain of the voting booth (88/93.3), machine (3/6.7), box (1), blinds (1), screen (1).

139. The performer bowed to the audience (88/96.7), crowd (7/3.3), applause (3), ground (1), performance (1).

140. He put the cigarette out in the ashtray (8/80), tray (6/6.7), sand (2), water (1), grass (1), floor (1), toilet (1), street ${ }^{*}(3.3)$, lobby* (3.3), cup* (1), pack (3.3).

141. The natives danced around the fire (87/76.7), circle (2), clock (1), girl (1), flame (1), floor (1), pot (1), sacrifice (1), totem pole (1), visitor (1), camp (1), pole (1/10), maypole $^{*}(3.3)$, captive* $(3.3)$, bonfire* $(3.3)$, tree* $(3.3)$.

142. They started down the ski slope (87/86.7), hill (4/3.3), jump (3), racing (1), lift (1), ramp (1), run (1), trail (1/10).

143. The yo-yo had a knot in the string (87/66.7), cord (6/16.7), end (4/3.3), middle (2/3.3), bottom (1), twine (1), elastic* (3.3), rope* (3.3).

144. The ice cream was topped with a red cherry (86/83.3), sprinkles (4), syrup (4/3.3), strawberries (2), berries (1), frosting (1), jimmies (1), raspberries* (36.7), sauce (3.3).

145. I went to the gym to get some exercise (86/90), experience (2), muscles (2), weights (2), practice (1), relief (1), shorts (1), sweat (1), training (1), water (1), clothes (1), ice (1), equipment $^{*}(6.7)$, sneakers* $(3.3)$.

146. Raise the flag up the pole (86/93.3), flagpole (6/3.3), mast (6), hill (1), post (1), salute (1), roof (1), sky (1), staff* ${ }^{*}(3.3)$.

147. The witch flew off on her broom $(86 / 76.7)$, broomstick (12/23.3), stick (1).
148. The typist indented at the beginning of a paragraph $(86 / 80)$, sentence $(6 / 10)$, letter (2/3.3), dictation (1), margin (1), line* (6.7).

149. His mother thought he was telling a lie (86/86.7), fib (5/6.7), joke (4), story (3/3.3), tale (1/3.3), truth (1).

150. Most watches are worn on the wrist (86/93.3), arm (6), left (3/3.3), right (2), hand (1), band (1), edge (1), left arm* (3.3).

151. The pirate buried a treasure chest $(86 / 80)$, box $(5 / 6.7)$, map (2), alone (1), hunt (1), secretly (1), there (1), underground (1), safely* (3.3), trove* (3.3).

152. Doonesbury is his favorite comic strip (86/86.7), book (5), character (4/10), story (2), actor (1), cartoon* (3.3).

153. All her music was on cassette tape (85/86.7), recorder (6), player (4/6.7), deck (1), disk (1/3.3), disk players (1), records* (3.3).

154. The visitors rang the bell (85/83.3), doorbell (15/13.3).

155. Sue put on her shoes and socks (85/70), coat (3), clothes (1), dress (1), feet (1), hat (1/3.3), gloves (1/3.3), left (1/3.3), stockings (1/16.7), hose* (3.3).

156. She was leaving on a two week vacation $(85 / 90)$, cruise (8/3.3), tour (2/3.3), trip (1/3.3), holiday (1), notice (1).

157. She liked to paint with water colors $(85 / 80)$, paints $(13 / 16.7)$.

158 . He cleared his throat to catch their attention $(85 / 70)$, breath (5/10), story (2), train (2), bouquet (1), voice (1), words (1), question (1), eye* $(6.7)$, reaction* ${ }^{*}(3.3)$.

159. We heard the morning news on the radio (85/93.3), TV (10/3.3), television (4/3.3).

160. The wolves howled at the moon (84/76.7), sheep (3), night (2/3.3), campers (1), dog (1), hunters (1), intruders (1), noise (1), people (1/6.7), sound (1), tigers (1), dark (1), wind* (3.3), man* (3.3), dragon* (3.3).

161. For dessert he had apple pie (84/76.7), strudel (5), tart (2), turnover (1/3.3), cake (1), crisp (1), crumb (1), custard (1), juice (1), sauce (1/10), cobbler* (1/3.3), dumpling* (1/6.7).

162. He awoke from a sound sleep (84/100), alarm (4), outside (2), suddenly (1), afar (1), crashing (1), blast (1), last night (1), of thunder (1), thumping (1), nap (1).

163. We drink milk that comes from a cow (82/73.3), carton (9/3.3), container (3/10), bottle (2/13.3), dairy (2), box (1), store (1).

164. The pond was full of croaking frogs (82/93.3), toads (9), ducks (5/3.3), birds (1), bullfrogs (1), fish (1), mud (1).

165. She hooked the leash to the dog's collar (82/83.3), neck (16/13.3), chain (1), throat* (3.3).

166. The bird of peace is the dove (82/93.3), eagle (5), symbol (3), anthem (1), king (1), lovely (1), messiah (1), one (1), phoenix (1), pigeon (1), savior (1), sign (1), sparrow (1), emblem* ${ }^{*}(3.3)$, prettiest* $(3.3)$.

167. The house was made of red brick (81/90), wood (13/6.7), clay (2), oak (1), plywood (1), stone (1), shingles (1/3.3).

168. The farm had a red barn $(81 / 90)$, hen $(2 / 6.7)$, roof (2), silo (2), tractor (2), chicken (1), cow (1), door (1), gate (1), hat (1), rooster (1), fence (1), coral* (3.3).

169. Every morning she walked the $\operatorname{dog}(81 / 70)$, busstop (2), route (2), bridge (1), esplanade (1), highway (1/3.3), floor (1), lake (1), park (1/3.3), path (1), plank (1), store (1/3.3), street (1), tightrope (1), trail (1/3.3), bus* (3.3), station* (3.3), train* $^{*}(3.3)$

170. Watermelons have a lot of seeds (80/73.3), pits (16/20), juice $(2 / 3.3)$, vitamins $(1)$, water $(1 / 3.3)$.

171. The king and queen laughed at the court jester (80/96.7), clown (3), ball (2), officer (2), yard (2), beggars (1), case (1), charges (1), decisions (1), house (1), judge (1), 
meeting (1), people (1), room (1), ship (1), joker (1), martial* (3.3).

172. The boy pulled the puppy's tail (79/96.7), ears (10), chain (1), collar (1), paw (1), tongue (1), nose (1), hair (1).

173. The dealer shuffled the cards (79/86.7), deck (19/6.7), merchandise (1), paper (1).

174. The thief was caught and sent to jail $(78 / 80)$, prison $(22 / 20)$.

175. He had to rake the leaves $(77 / 56.7)$, lawn (13/26.7), yard (6/3.3), garden (2/3.3), grass (2/6.7), coals* (3.3).

176. There were only three days until his birthday (77/80), graduation (5/6.7), vacation (3), death (2), exam (2/3.3), final (2), xmas (2), departure (1), execution (1), promotion (1), release (1), resurrection (1), trial (1) wedding (1), test* (3.3), school* $^{*}(3.3)$.

177. The detectives searched for a clue (77/73.3), suspect $(4 / 6.7)$, criminal (3/3.3), gun (3/6.7), killer (3), motive (2/6.7), murderer (2), weapon (2), crook (1), knife (1), man (1), thief $(1 / 3.3)$.

178. It was a nice day for a walk in the park (76/73.3), woods (17/6.7), country (3/6.7), sun (3/6.7), pasture (1/6.7), gar$\operatorname{den}^{*}(6.7)$

179. The baseball game was canceled because of the rain (75/53.3), weather (19/33.3), storm (5/6.7), heavy rain (1), quake* (3.3), earthquake* (3.3).

180. The little lost girl cried for her mother (75/93.3), mommy (9), mom (9/3.3), parents (3/3.3), dog (1), father (1), help (1), life (1).

181. He loved mashed potatoes and gravy (75/60), steak (6/13.3), meat (4/3.3), butter (4), corn (4), chicken (1), franks (1), hamburgers (1), meatloaf (1), peas (1/3.3), rice (1), spinach (1/3.3), onions* (3.3), sour cream* (3.3), carrots* $^{*}$ (3.3).

182. The lion is the king of the jungle (74/60), beasts $(9 / 23.3)$, forest (8/10), animals (4/6.7), castle (2), desert, earth, wild.

183. He used a screw driver to jimmy the lock (74/83.3), door (16/6.7), board (1), bolt (1), cork (1), engine (1), ignition (1), lid (1), nails (1), screw (1), wheel (1), window (1/10).

184. The salesman wanted to make a sale (73/93.3), deal (15/6.7), profit (3), pitch (2), commission (1), purchase (1), buck (1), killing (1).

185. She took a picture with her camera (72/86.7), friend $(9 / 3.3)$, boyfriend (5/3.3), mother (4), baby (1), daughter (1/3.3), doctor (1), family (1), father (1), husband (1), sister (1), yesterday (1), parents (1), mom (1), brownie* (3.3).
186. The swimmer dove into the pool (72/83.3), lake (9/6.7), pond (7/6.7), water (5/3.3), ocean (1), sea (1).

187. Paul took a bath in the $t u b(70 / 50)$, lake (5/10), morning $(4 / 6.7)$, river (3), water $(3 / 3.3)$, bathtub (2), bathroom $(2 / 6.7)$, rain (2), creek (1/10), evening (1/3.3), forest (1/3.3), hotel (1), pond (1), pool (1), shower (1), sea (1), stream (1),

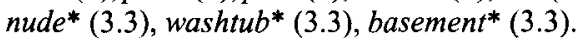

188. The surgeon scrubbed up before the operation $(67 / 86.7)$, surgery (33/13.3).

189. Banks keep their money in a vault (67/86.7), safe (32/13.3), account (1).

190. The teenager talked on the phone $(63 / 66.7)$, telephone (30/23.3), bus (1), curb (1), microphone (1), mike (1), rope (1), show (1), track (1), class* (3.3), stage* (3.3).

191. He was reading a paperback book (62/86.7), novel (37/13.3), magazine (1).

192. She wore a garter on her leg $(60 / 76.7)$, thigh $(21 / 13.3)$, belt (5), stocking (5/3.3), date (2), hips (2), belly (1), girdle (1), shoulder (1), stomach (1), waist (1), knee* (3.3), sleeve* (3.3).

193. The actress gave $10 \%$ to her agent (56/83.3), manager (14/6.7), charity (5/3.3), income (3), mother (2), performance (2), salary (2), assistant (1), audience (1), boss (1), check (1), church (1), earnings (1), fans (1), crew (1), husband (1), income (1), kids (1), lawyer (1), money (1), promoter (1), time (1), understudy (1), coactresses* (3.3), pay* (3.3).

194. The bride wore a white gown (52/66.7), dress (44/23.3), veil (4/6.7), satin* (3.3).

195. The bar window had a neon sign (52/96.7), light (46/3.3), tinge (1), view (1).

196. The package was wrapped in a plain brown bag (49/50), wrapper (30/10), paper (15/33.3), wrapping (3/3.3), box (1), bow (1), paper bag (1), envelope* (3.3).

197. The cabin was made of logs (48/73.3), wood (46/16.7), brick (2), lumber (1), oak (1), pine (1/3.3), wood logs (1), redwood $^{*}(1 / 3.3)$, fiberglass* (1/3.3).

198. The chicks followed their mother hen $(38 / 76.7)$, home $(36 / 10)$, closely (5/3.3), around (4/3.3), everywhere (4/3.3), chicken (2), duck (1), example (1), footstep (1), goose (1), instinctively (1), instructions (1), lead (1), quickly (1), quietly (1), relentlessly (1).

(Manuscript received November 4, 1993; revision accepted for publication January 5,1995 .) 